\title{
Canadian Association of Gastroenterology - Canadian Institutes of Health Research - pharmaceutical partner* postdoctoral operating fellowship programme: An outstanding success that continues to excel!
}

\author{
Derek M McKay PhD ${ }^{1}$, Sandra Daniels MSc ${ }^{2}$
}

\begin{abstract}
DM McKay, S Daniels. Canadian Association of Gastroenterology - Canadian Institutes of Health Research pharmaceutical partner* postdoctoral operating fellowship programme: An outstanding success that continues to excel! Can J Gastroenterol 2003;17(7):437-439.

The Canadian Association of Gastroenterology (CAG) post-doctoral fellowship programme was initiated in 1992 with the goal of promoting excellence in Canadian gastroenterological research. With backing from multiple pharmaceutical partners and the Canadian Institutes of Health Research, 87 fellows were funded over the next ten years for a total investment of $\$ 8,730,101$. Between 1992 and 2000, fellows authored 247 articles; 176 being original research articles, $31(17.5 \%)$ of which appeared in journals with impact factors of greater than 10. As testament to the program's success in developing young scientists, 31 former fellows (36\%) have progressed to faculty positions. The fellowship programme continues to be an outstanding success and the flagship of CAG research activities.
\end{abstract}

Key Words: CAG; CIHR; Fellow training; Promoting research; Research investment; Research partners
Le programme de bourse d'exploitation postdoctorale de l'Association canadienne de gastroentérologie et des Instituts de recherche en santé du Canada avec des partenaires pharmaceutiques : Un succès retentissant qui continue d'exceller

Le programme de bourses postdoctorales de l'Association canadienne de gastroentérologie (ACG) a été lancé en 1992 afin de promouvoir l'excellence en recherche en gastroentérologie au Canada. Avec le soutien de multiples partenaires pharmaceutiques et des Instituts de recherche en santé du Canada, 87 boursiers ont été subventionnés au cours des dix années suivantes, pour un investissement total de 87730101 \$. Entre 1992 et 2000, les boursiers ont rédigé 247 articles, dont 176 articles de recherche originaux, et 301 (17,5\%) d'entre eux ont été publiés dans des journaux scientifiques dont le facteur de répercussion est supérieur à 10. Pour prouver le succès du programme à former de jeunes scientifiques, 31 anciens boursiers (36\%) ont obtenu des postes de professeur universitaire. Le programme de bourse continue de constituer un succès retentissant et d'être le porte-étendard des activités de recherche de l'ACG. n 1992, the Canadian Association of Gastroenterology
(CAG) with support from pharmaceutical partners (initially
Janssen-Ortho Inc then AstraZeneca Canada Inc) launched a
post-doctoral fellowship programme with the central goals of
promoting excellence in research in Canadian gastroenterolo-
gy, hepatology and related disciplines, and broadening the
research infrastructure in these areas across Canada. In 2000,
in agreement with the Canadian Institutes of Health Research
(CIHR: formerly the Medical Research Council of Canada), a
1:1 funding partnership was implemented with CIHR
Research and Development and the growing list of CAG's
Partners (see acknowledgements). The aim was to maintain
the CAG Operating Fellowship Programme as an innovative
and effective means to nurture junior clinicians and PhD sci-
entists with interests in intestinal health and disease processes.
A decade later, follow-up data have been collated on all but one of the fellows who have been supported by this fellowship programme. The synopsis of the data presented herein is testimony to the truly outstanding success of the fellowship programme. As current Chair of the CAG Research Committee, it is a privilege to be able to present the success of the fellowship programme to the CAG membership at large, and to acknowledge and thank CIHR and all of the partners that have supported, and continue to support, the training of talented post-doctoral fellows through the CAG Operating Fellowship Programme. Thank you!

Between 1992 and 2002, 87 research fellows have been supported with a total investment of $\$ 8,730,101$ $\$ 3,214,976$ from CIHR and $\$ 5,515,125$ from our partners (Figure 1). Figure 2 shows that approximately equal num-

${ }^{1}$ Intestinal Disease Research Programme, McMaster University, Hamilton, Ontario; ${ }^{2}$ Canadian Association of Gastroenterology National Office, Oakville, Ontario

Correspondence and reprints: Dr Derek M McKay, Intestinal Disease Research Programme, HSC-3N5C, McMaster University, 1200 Main Street West, Hamilton, Ontario L8N 325. Telephone 905-525-9140 ext 22588, fax 905-522-3454, e-mail mckayd@mcmaster.ca

* Partners: Abbott Laboratories Ltd, ALTANA Pharma, AstraZeneca Canada Inc, Axcan Pharma Inc, Carsen Group Inc, Crohn's and Colitis Foundation of Canada (CCFC), Ferring Pharmaceuticals, GlaxoSmithKline, Janssen-Ortho Inc, Novartis and Bristol Myers Squibb, Schering Canada Inc, Solvay Pharma Inc

Received for publication March 6, 2003. Accepted March 31, 2003 


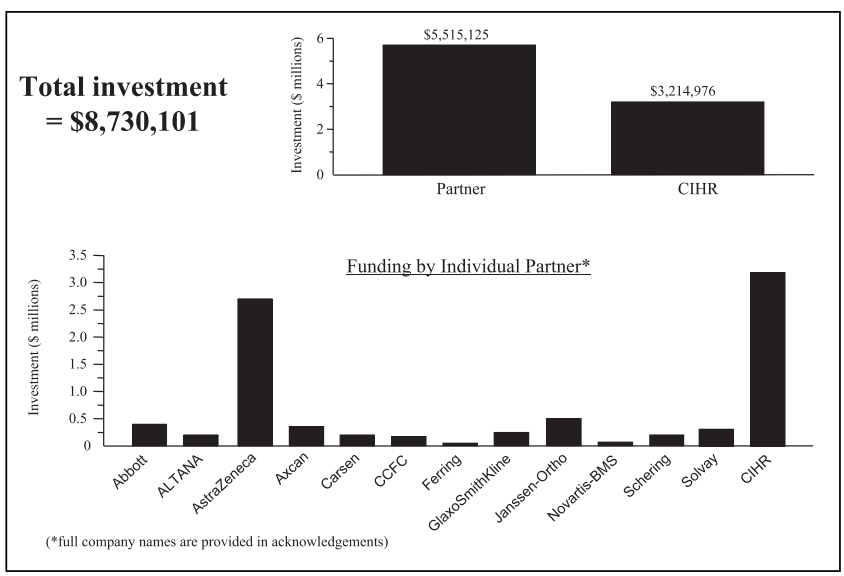

Figure 1) Total investment and distribution by funding partner in the Canadian Association of Gastroenterology Operating Fellowship Programme (1992-2002). CIHR Canadian Institutes of Health Research

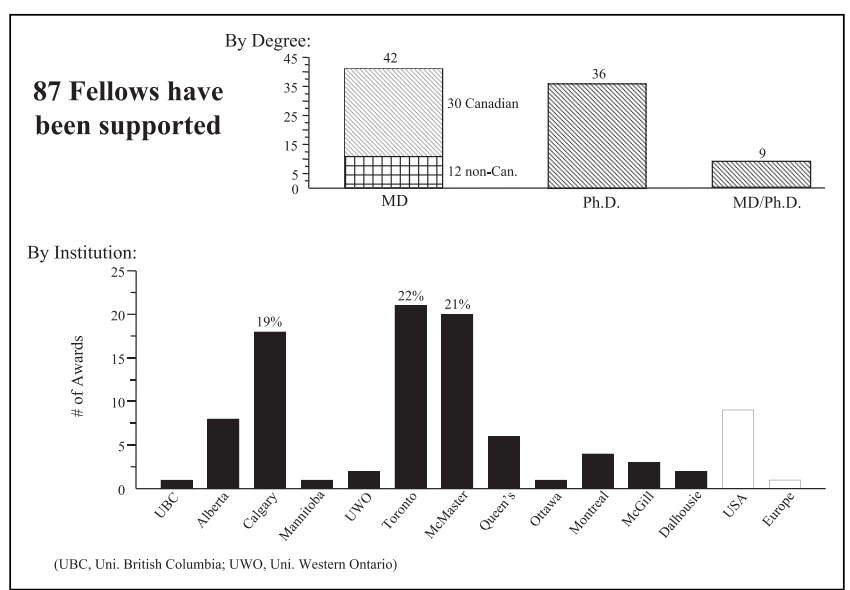

Figure 2) Distribution of Canadian Institutes of Health Research/Partnered/Canadian Association of Gastroenterology Operating Fellowships by applicants' degree and Canadian institution (1992-2002)

bers of $\mathrm{MD}$ and $\mathrm{PhD}$ fellows were successful in achieving funding, with the lower panel illustrating the distribution of the fellowships by institution. The concentration at the University of Calgary, University of Toronto and McMaster University reflects the greater number of applications from these institutions, which in turn is likely a consequence of the greater number of faculty active in gastroenterological research at these sites.

With such impressive investment in the fellowship programme, one must ask whether this investment has enhanced Canadian research in gastroenterology and related disciplines. The unequivocal and resounding answer is yes. Of the 87 individuals funded, 31 (36\%) now hold faculty positions and twothirds of these are at Canadian institutions. Moreover, of those fellows who have secured a faculty position, 14 (42\%) hold PhDs, 14 (42\%) hold MDs and three (16\%) hold both MD and $\mathrm{PhD}$ degrees. Figure 3 shows the status of the remaining $56(64 \%)$ fellows who received support through this CAG programme, and it is noteworthy that $44 \%$ of all fellows are currently conducting post-doctoral research fellowships. Not only have $36 \%$ of the fellowship awardees secured faculty positions, some - such as Drs N Jones (University of Toronto), K Madsen

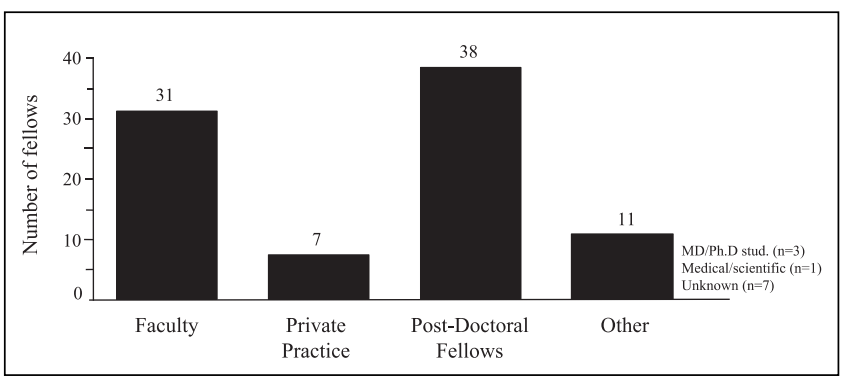

Figure 3) Current known status of Canadian Association of Gastroenterology-supported fellows

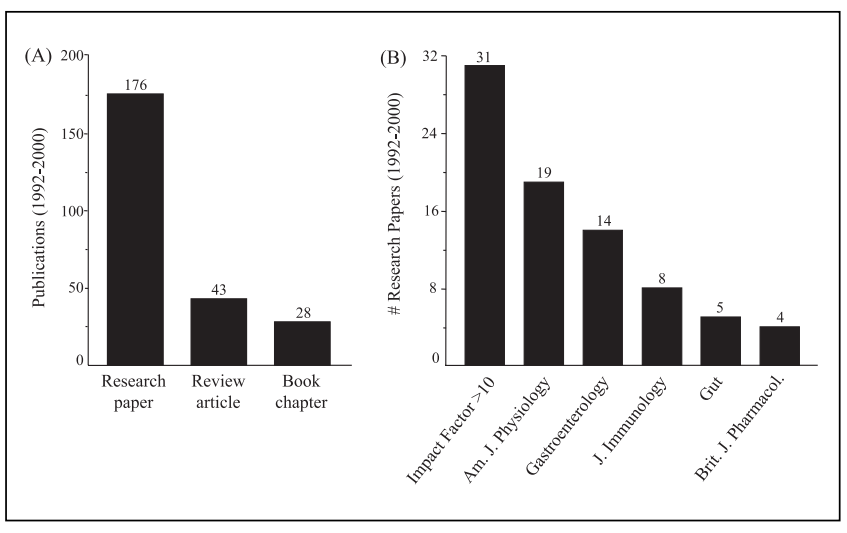

Figure 4) Canadian Association of Gastroenterology Operating Fellowship productivity (1992-2000): A) total publications and B) selected high impact scientific journals

(University of Alberta) and $\mathrm{N}$ Vergnolle (University of Calgary) - have, in turn, become supervisors of programmefunded fellows. Others, such as Drs N Abraham (Dalhousie University), D Armstrong (McMaster University), K Jacobson (University of British Columbia) and J Marshall (McMaster University) are members of CAG committees, with the opportunity to contribute to the continued success of not only the research fellowship programme, but the CAG in general.

An often used index of scientific success is publication rate and publication quality. CAG fellows have performed admirably on both counts (Figure 4). The funded fellows (1992 to 2000) have been first or contributing author on 247 publications, 176 of which are original research articles: 139 of these appeared in 65 different citation-impact indexed journals (it is noteworthy that these numbers underestimate the productivity of fellows since they span the period 1992 to 2000 , whereas the funding information presented herein is for 1992 to 2002). Add to this approximately 320 published abstracts (and concomitant presentations at national and international conferences) and it is clear that the fellows have been prolific. But what of the quality of these publications? Using the citation impact factor as an indicator of publication quality, 31 $(17.5 \%)$ of the original research papers have appeared in journals with impact factors greater than 10 . This is a remarkable achievement for any subspeciality group. Moreover, 33 papers (19\%) were published in The American Journal of Physiology (impact factor approximately 3.8) or Gastroenterology (impact factor approximately 13.1), the two major journals for gastrointestinal research papers. 
There is another less tangible, but no less important, impact of the CAG Operating Fellowship Programme. The CAG fellows have been tremendous assets to the laboratories they joined, independent of whether their supervisor was an experienced mainstay of the CAG or at the assistant professor level. While difficult to formally assess, the additional critical mass and infrastructure created by the CAG Operating Fellowship Programme aided junior faculty as they established their independent research laboratories, provided support and research resources for more senior investigators, and undoubtedly bolstered the international impact of Canadian gastroenterological research.

In essence, what began as a fledgling innovative idea - the CAG Operating Fellowship - has matured into an outstanding success, and is now the flagship program of CAG research activities. Eighteen new fellowships and two fellow-to-faculty awards (a new program to bridge talented fellows with two to four years postdoctoral training into full-time faculty positions), effective July 2003, were presented at an awards ceremony held at the CAG-Canadian Digestive Diseases Week Conference (February 24, 2003) and this bodes well for meeting one of the major mandates of the CAG: to build, in collaboration with CIHR and our Partners, Canadian capacity and expertise in the discipline of gastroenterology and nutri- tion, and to promote excellence in research. Laudable progress has been made and we must now strive to sustain the momentum that has been generated in the CAG Operating Fellowship Programme and create complementary means to highlight the value of, and need for, continued investment in gastroenterological research in Canada.

Finally, on behalf of the Canadian Association of Gastroenterology, I would reiterate our appreciation and sincere thanks to CIHR and all of the Partners for their longstanding support of the CAG Operating Fellowship Programme. All parties involved with this program, both sponsors and researchers, are to be congratulated.

ACKNOWLEDGEMENTS: Comments by Drs PM Sherman (President, CAG) and D Leddin (President Elect, CAG) and Mr P Sinclair (National Executive Director, CAG) are gratefully acknowledged. Financial support for the operating fellowships provided by Canadian Institutes of Health Research (CIHR) and the CAG partners (Abbott Laboratories Ltd, ALTANA Pharma, AstraZeneca Canada Inc, Axcan Pharma Inc, Carsen Group Inc, Crohn's and Colitis Foundation of Canada (CCFC), Ferring Pharmaceuticals, GlaxoSmithKline, Janssen-Ortho Inc, Novartis and Bristol Myers Squibb, Schering Canada Inc, and Solvay Pharma Inc) is greatly appreciated 


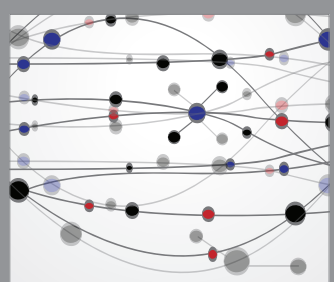

The Scientific World Journal
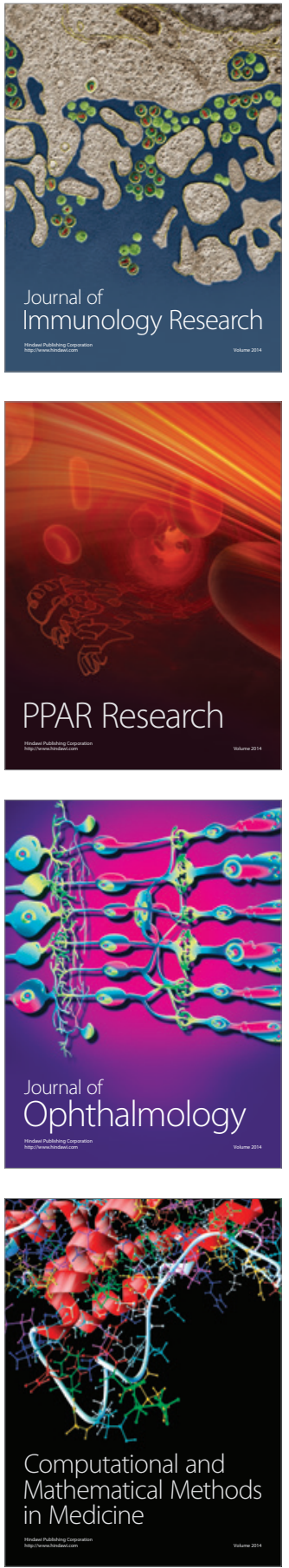

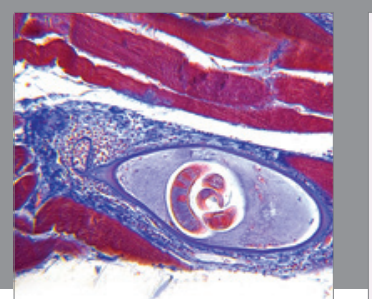

Gastroenterology Research and Practice

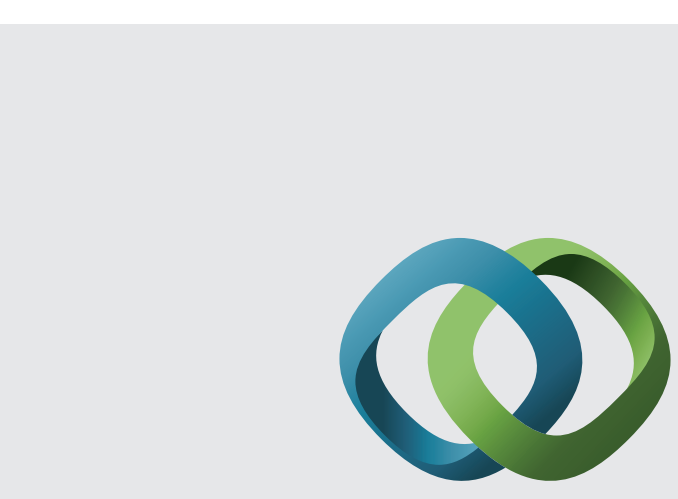

\section{Hindawi}

Submit your manuscripts at

http://www.hindawi.com
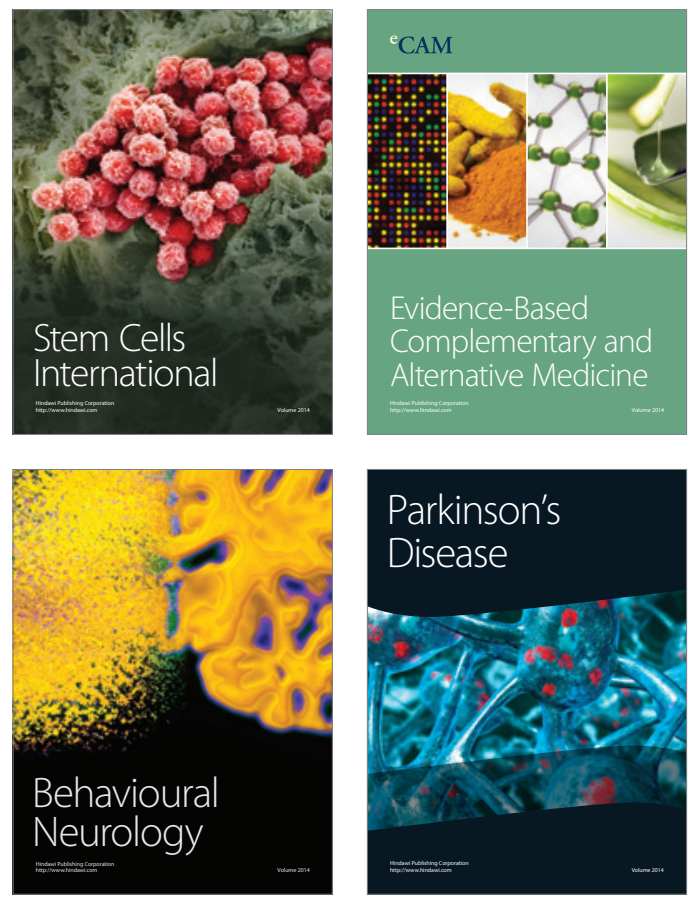
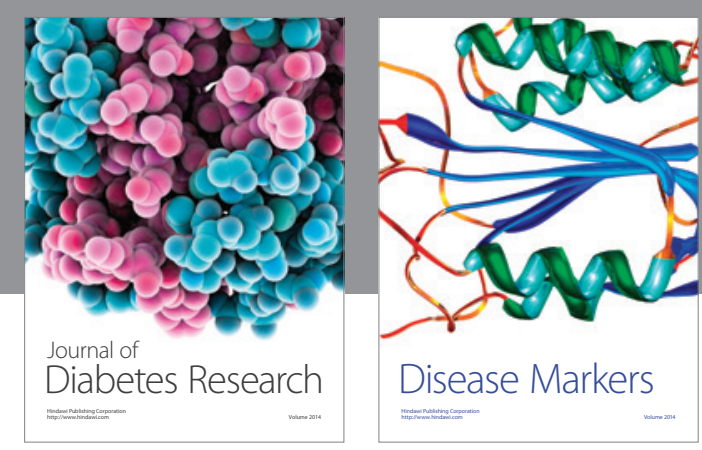

Disease Markers
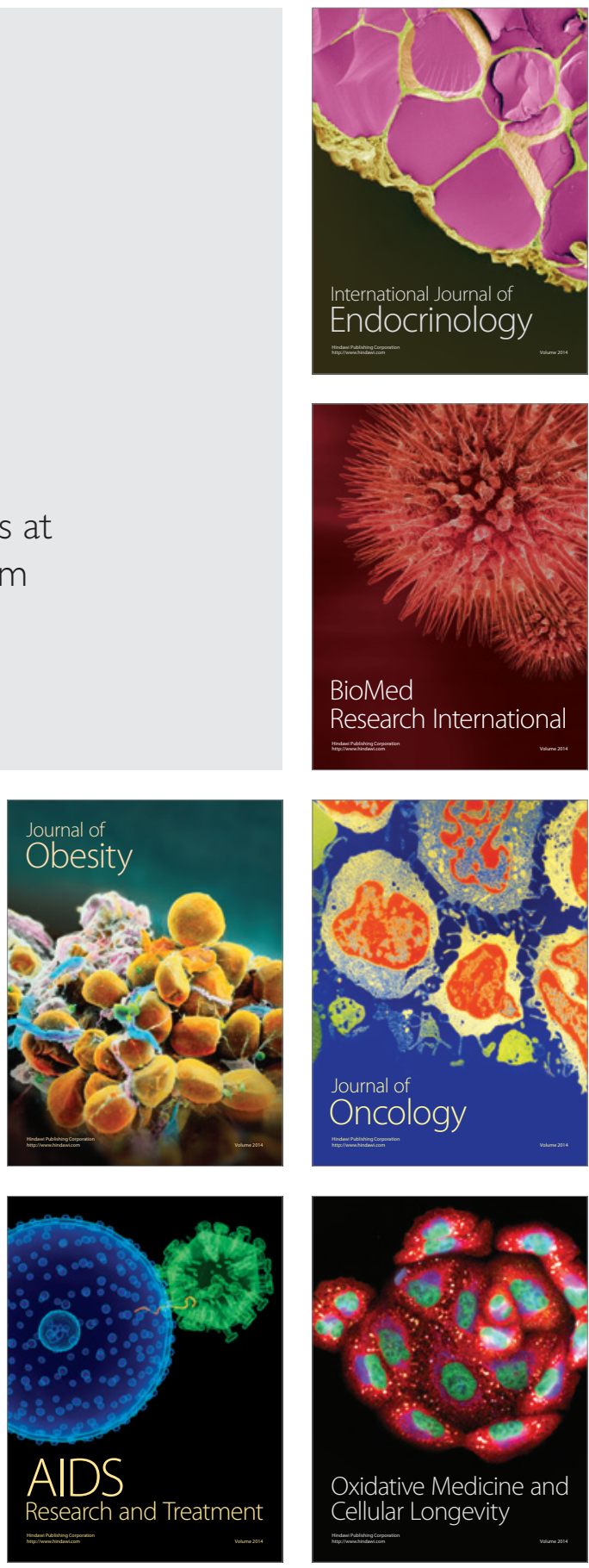